\title{
Testing population differentiation in plant species - how important are environmental maternal effects
}

\author{
Armin Bischoff and Heinz Müller-Schärer \\ A. Bischoff (armin.bischoff@agrocampus-ouest.fr) and H. Müller-Schärer, Dept of Biology, Univ. of Fribourg, Chemin du musée 10, CH-1700 \\ Fribourg, Switzerland. Present address for AB: Agrocampus West, Centre of Angers, Natl Inst. of Horticulture and Landscape Planning (INHP), \\ UMR 1099 B:03P, 2 rue André Le Nôtre, FR-49045, France.
}

\begin{abstract}
The maternal environment may contribute to population differentiation in offspring traits if growing conditions of mother plants are different. However, the magnitude of such environmental maternal effects compared with genetic differentiation is often not clear. We tested the importance of environmental maternal effects by comparing population differentiation in parental seed directly collected in the field and in $\mathrm{F}_{1}$ seed grown under homogeneous conditions. The $\mathrm{F}_{1}$ seeds were obtained by random crosses within populations. We used five populations in each of four plant species to analyse seed mass and growth chamber germination of both generations at the same time. In two species, we additionally tested offspring performance in the field. We found a significant population differentiation in all species and for nearly all measured traits. Population-by-generation interactions indicating environmental maternal effects were significant for germination (three species) and for seed mass (two species) but not for growth and reproduction. The significant interaction was partly due to a reduction of among-population differentiation from the parental to the $\mathrm{F}_{1}$ generation that can be explained by a decrease of maternal provisioning effects. However, in some species by trait combinations a change in population ranking and not a decrease of variation was responsible for significant population-by-generation interactions indicating environmental maternal effects beyond maternal provisioning. Fitting of seed mass as covariate was not successful in reducing environmental maternal effects on population differentiation in germination. We discuss alternative methods to account for environmental maternal effects in studies on genetic differentiation among populations.
\end{abstract}

The maternal environment can affect offspring fitness independent of the maternal genotype and may be a source of bias in studies on genetic differentiation among populations (Roach and Wulff 1987, Donohue and Schmitt 1998, Bischoff et al. 2006a, Riginos et al. 2007). Environmental maternal effects are well documented for early stages of plant development such as seed mass and germination (Gutterman 1992, Sultan 1996, Baskin and Baskin 1998) and often decline later in the life cycle (Roach and Wulff 1987, Agrawal 2002, Hereford and Moriuchi 2005). However, there are also several studies that demonstrated the persistence of maternal effects over the whole life cycle (Helenurm and Schaal 1996), or even into subsequent generations (Wulff et al. 1999).

Maternal plants have a stronger effect on offspring fitness than paternal plants because they provide nourishment of the seeds, two-thirds of the endosperm genetic material (most Angiosperms) and the extranuclear DNA in mitochondria and plastids of the embryo (Roach and Wulff 1987, Schmid and Dolt 1994, Galloway 2001). While the maternal contribution to extranuclear DNA and endosperm constitute a part of the genetic variability in offspring traits, the maternal provisioning of the embryo may strongly depend on the maternal environment. It is well known that an increased allocation of maternal resources (nutrients, water, light) improves seed quality and germination resulting in a fitness advantage that may persist until maturity, in particular in stressful, competitive environments (Sultan 1996, Donohue and Schmitt 1998, Riginos et al. 2007). Moreover, non-resource factors like temperature, light quality and daylenght during seed development affect offspring traits (Roach and Wulff 1987, Baskin and Baskin 1998, Munir et al. 2001, Donohue et al. 2005). Such environmental maternal effects that are not directly mediated by maternal provisioning contribute to transgenerational plasticity that may be adaptive if the offspring environment is predictable and similar to the maternal environment (Galloway and Etterson 2007, Marshall and Uller 2007, Rhode and Juntilla 2008). This includes the induction of resistance traits against herbivores that can be transferred from mother plants to their progeny (Agrawal 2002, Holeski 2007). Changes in phytohormones, nutrient content and structure of the seed coat, which is entirely maternal tissue, have been suggested as potential drivers of transgenerational plasticity (Roach and Wulf 1987, Baskin and Baskin 1998, Munir et al. 2001). More recently, several authors have discussed the involvement of epigenetic processes in environmental maternal effects (Bossdorf et al. 2008, Rohde and Juntilla 2008). Mediated by DNA methylation, changes in chromatin structure or small, non-coding RNA molecules, the activity of genes can be largely reduced or increased. Environmentally induced epigenetic changes in gene activity 
may be stable for several generations and can also be transmitted by the paternal crossing partner (Kalisz and Purugganan 2004, Molinier et al. 2006). Significant effects of the paternal environment on offspring traits have been reported in several studies but they are smaller than maternal environmental effects (Roach and Wulff 1987, Schmid and Dolt 1994, Galloway 2001). In our study, we keep the term maternal environmental effects although offspring performance may be driven by the environment of both parents. We assume that at the chosen spatial scales, environmental differences between populations are much larger than between mother and father plants as most flowers receive pollen from close neighbours (Slatkin 1985, Hardy et al. 2004).

Several methods to control for environmental effects in quantitative genetic studies have been proposed. The most common one is the correction of population differences by fitting seed mass as a covariate, which is largely affected by the maternal environment (Pico et al. 2004, Hereford and Moriuchi 2005, Bischoff et al. 2006a). Although accounting for differences in seed size can partially reduce variation due to differential maternal provisioning, it remains unclear whether this method also accounts for adaptive transgenerational plasticity driven by non-resource environmental cues. A second approach is to only use juvenile plants of the same size and developmental stage in experiments on genetic differentiation or to correct for initial plant size (Becker et al. 2006, Macel et al. 2007). Controlling for variation in early stages of plant development can largely reduce the bias due to environmental maternal effects but information on genetic differentiation in these early traits is lost. Growing plants for one or several generations under standardized conditions before starting experiments is a third method to account for environmental maternal effects (Galloway and Fenster 2000, Santamaria et al. 2003). This approach has predominantly been applied to annual species as growing a $F_{1}$ generation is cumbersome in many perennials.

Studies quantifying the dimension of environmental maternal effects compared with genetic differentiation among populations are required to evaluate the need for control. Experiments testing the same genotypes in different environments have demonstrated a considerable contribution of non-genetic maternal effects on offspring phenotypes that was in some cases smaller (Weiner et al. 1997, Hereford and Moriuchi 2005, Holeski 2007) and in others greater than the genotype effect (Schmid and Dolt 1994, Sultan 1996). However, there is a lack of studies assessing the contribution of non-genetic effects of the natural maternal environment on population differentiation and local adaptation.

In our study, we compared the performance of different plant populations grown from $\mathrm{F}_{1}$ seed produced under standardized conditions in a common garden with those from their corresponding field collected parental seeds. Although persistence of maternal effects in subsequent generations has been reported (Wulff et al. 1999), environmental effects are usually transitory and disappear already in the $\mathrm{F}_{1}$ generation, especially if the maternal and progeny environment are different (Agrawal 2002, Gianoli 2002). Maternal effects induced by the environment of the collection sites can therefore be assumed to have diminished after one generation of growth under homogeneous conditions and a significant population-by-generation interaction would indicate such a non-genetic component of population differentiation. We further tested whether a potential generation-by-population interaction can be explained by among-population differences in seed mass. Specifically, we ask: (1) how important are environmental maternal effects in population differentiation of progeny grown under homogeneous conditions? (2) Does the contribution of environmental maternal effects to differentiation in offspring traits depend on the developmental stage? (3) Can the contribution of environmental maternal effects be explained by differences in seed mass?

\section{Material and methods}

\section{Study species and populations}

We selected four species that represent different life cycle types: the annual Legousia speculum-veneris (Primulaceae), the biennial Echium vulgare (Boraginaceae), the short-lived biennial or perennial Cichorium intybus (Asteraceae) and the long-lived perennial Origanum vulgare (Lamiaceae). All four species are predominantly outcrossing but in $L$. speculum-veneris, E. vulgare and $C$. intybus selfing is possible. The species are frequently translocated for restoration purposes in Switzerland (Bischoff et al. in press) and thus, an improved knowledge on the potential contribution of environmental maternal effects to population differentiation has also strong practical implications.

In autumn 2001, we sampled four populations of each species across an atlantic-continental gradient (Table 1). The local western Swiss (west $\mathrm{CH}$ ) and the eastern Swiss (east $\mathrm{CH}$ ) populations are characterized by a subatlantic climate with high rainfall (1000-1250 $\left.\mathrm{mm} \mathrm{year}^{-1}\right)$. The southern German population (south D) originates from a subatlantic climate with average rainfall $\left(650-850 \mathrm{~mm}\right.$ year $\left.^{-1}\right)$ and the central German one (central D) from a subcontinental climate with low rainfall (450-500 $\left.\mathrm{mm}^{-1} \mathrm{yr}^{-1}\right)$. Seeds of $E$. vulgare and $O$. vulgare were additionally sampled from the UK representing a typical atlantic climate with mild winters.

Table 1. Provenance and description of study populations. ${ }^{1}$ Echium vulgare. ${ }^{2}$ Origanum vulgare.

\begin{tabular}{lllll}
\hline & \multicolumn{1}{c}{ Collection site } & Source & Coordinates & Climate, humidity \\
\hline West $\mathrm{CH}$ & Fribourg area (west Switzerland) & wild & $46^{\circ} 51^{\prime} \mathrm{N}, 07^{\circ} 10^{\prime} \mathrm{E}$ & subatlantic, moist \\
East CH & Winterthur area (east Switzerland) & stock & $47^{\circ} 30^{\prime} \mathrm{N}, 08^{\circ} 43^{\prime} \mathrm{E}^{2}$ & subatlantic, moist \\
South D & south Hesse, Baden (south Germany) & stock & $49^{\circ} 52^{\prime} \mathrm{N}, 08^{\circ} 39^{\prime} \mathrm{E}$ & subatlantic, medium \\
Central D & Sachsen-Anhalt (central Germany) & wild & $51^{\circ} 19^{\prime} \mathrm{N}, 11^{\circ} 54^{\prime} \mathrm{E}$ & subcontinental, dry \\
UK & Sommerset (southwest England) & stock & $51^{\circ} 06^{\prime} \mathrm{N}, 03^{\circ} 02^{\prime} \mathrm{W}$ & Atlantic, medium \\
& Norfolk (east England) & & $52^{\circ} 40^{\prime} \mathrm{N}, 00^{\circ} 57^{\prime} \mathrm{E}$ & \\
\hline
\end{tabular}


Legousia speculum-veneris seeds were only available from west $\mathrm{CH}$, east $\mathrm{CH}$ and south $\mathrm{D}$. West $\mathrm{CH}$ and central D seeds were directly collected in the wild, seeds of the other populations were provided by companies specialized in wild seed production. Only seed suppliers were chosen who could give information on the original collection site and who regularly replace stocks by wild collections.

\section{Growth of $F_{1}$ seed}

In spring 2002 seeds of all populations were germinated in petri dishes filled with a $0.5 \mathrm{~cm}$ layer of agar (1\% agar) and placed in growth chambers providing homogeneous conditions. Temperature and day length were adjusted to optimum conditions determined in a previous test, which was $13 \mathrm{~h}$ dark, $5^{\circ} \mathrm{C}$ and $11 \mathrm{~h}$ light, $15^{\circ} \mathrm{C}$ for Legousia and $11 \mathrm{~h}$ dark, $10^{\circ} \mathrm{C}$ and $13 \mathrm{~h}$ light, $20^{\circ} \mathrm{C}$ for the other three species. All emerging seedlings were planted with a surrounding agar block into trays filled with garden soil and kept in the greenhouse. After two weeks 25 individual plants of each Echium, Cichorium and Origanum population were transplanted into pots, and placed in five garden plots each comprising five plants of the same population. For Legousia, the corresponding numbers were 60 plants per population and 12 plants per plot because plants are smaller and produce less seeds. Plants of different species but same provenance were grown in the same plots resulting in a total of 25 plots each comprising 27 plants. The plots were randomly arranged to avoid a confounding of population and potential position effects due to spatial heterogeneity. Before onset of flowering, all plots were covered with a nylon mesh cage ( $1 \mathrm{~mm}$ mesh size) to avoid cross pollination between the populations. The five plots comprising populations of the same provenance were left uncovered for five days to allow open pollination. Every five days the previously uncovered provenance was caged again and cages were removed from another provenance. This controlled pollination was performed in summers 2002 and 2003. Seeds of the annual Legousia were harvested in August 2002 and those of the biennials and perennials in September 2003.

\section{Comparison of parental and $F_{1}$ generation}

For all species and populations, we assessed differences in seed mass and germination percentage between parental and $\mathrm{F}_{1}$ generation. We selected Origanum as a perennial and Legousia as an annual species to also test for environmental maternal effects in later stages of the life cycle.

A subset of parental seeds was stored at room temperature during the growth of the $\mathrm{F}_{1}$ generation. In 2004, we simultaneously germinated parental and $\mathrm{F}_{1}$ seeds in growth chambers. Six-hundred seeds of each generation and population were weighed and distributed to 12 petri dishes each comprising 50 seeds. Germination conditions were the same as for the growth of $F_{1}$ seed. The petri dishes were arranged randomly within growth chambers and germination was recorded for six weeks. Germinated seeds (with visible radicule) were counted every three days and removed.

In parallel, we sowed Origanum seeds at a previously ploughed and harrowed field site close to Fribourg in western Switzerland in order to test for environmental maternal effects in later stages of the life cycle. Each population by generation combination was represented by one $2 \times$ $2 \mathrm{~m}$ plot in each of eight blocks. The plots comprised a central grid of 24 cells $\left(0.2 \times 0.2 \mathrm{~m}^{2}\right)$, and 16 seeds were sown to each grid cell. We recorded seedling emergence every six weeks and labelled the seedlings. After 12 weeks, the number of seedlings was reduced to one per grid cell, i.e. ideally 24 per plot, to reduce intraspecific competition. We kept plants of average size and removed later emerging seedlings. Moderate within treatment transplanting was used to avoid empty cells and to keep the number of plants per plot and treatment constant. Transplants were only considered for data analysis if they survived for at least eight weeks until late summer. The plots were carefully weeded to reduce interspecific competition. We analysed survival for all test plants and growth of five randomly selected focal plants per plot. We regularly recorded the number of leaves and the length of the longest shoot. In October 2004, the focal plants were harvested and biomass was measured after $48 \mathrm{~h}$ drying at $80^{\circ} \mathrm{C}$.

A similar design was chosen for Legousia but parental and $F_{1}$ seed were sown in different years (2002 and 2003). The experiment was planned as a control for the stability of population differentiation (Bischoff et al. 2006a). We are aware that population-by-generation interaction is confounded with a potential population-by-environment interaction as climatic conditions were quite different in the two years. Set-up and measurements were the same as for Origanum but we included the number of capsules as a measure of reproductive output.

\section{Statistical analysis}

We calculated a two-way fixed effects ANOVA to evaluate population and generation effects on Petri dish means of seed mass and germination percentage. Germination percentage is the fraction of seeds germinated in each petri-dish after six weeks of incubation. To achieve normality and homogeneity of variances, germination percentage was arcsin square root transformed. A significant generationby-population interaction indicates a contribution of environmental maternal effects to population differentiation. In the case of a significant interaction Tukey HSD posthoc tests were calculated separately for both generations in order to analyse which populations remain significantly different in the $\mathrm{F}_{1}$. We fitted seed mass as covariate to the ANOVA model to test whether environmental maternal effects on germination percentage are mediated by seed mass. The full model including seed mass as a covariate was compared with the reduced model without the covariate. A reduced F-value of the population-by-generation interaction in the full model indicates that such a correction for seed mass can reduce the contribution of environmental maternal effects to population differentiation. All analyses were calculated separately for each species as the full model revealed significant interactions of generation and population with species.

A similar two-way ANOVA was applied to the field data of Origanum and Legousia but in addition, block was included into the model and block means were used as response variable. Due to low seedling emergence, some block means of Origanum 
had to be calculated on only two instead of five plants per treatment (west $\mathrm{CH}$, both generations and east $\mathrm{CH}$ : parental seed). Field germination was arcsin square root transformed, and leaf number, shoot length, biomass and capsule number (Legousia) were log-transformed prior to analysis. Tukey HSD was applied in the same way as in the germination test.

In order to obtain more information on the nature of population-by-generation interactions, we calculated coefficients of variation (CV) among populations for both petri dish and field data. If environmental maternal effects significantly contribute to population differentiation and if they are only transitory as generally assumed, among populations $\mathrm{CV}$ are expected to decrease from the parental to the $\mathrm{F}_{1}$ generation.

\section{Results}

\section{Seed mass and germination under controlled conditions}

We found a strong population main effect on seed mass for Echium, Cichorium and Origanum (Table 2). The effect of generation was only significant for Origanum with $\mathrm{F}_{1}$ seed being smaller than parental seed. In Cichorium, and Legousia, the population-by-generation interaction was significant indicating a contribution of environmental maternal effects to population differentiation. Cichorium seeds of the east $\mathrm{CH}$ population had a significantly higher mass than those of other Cichorium populations ( $\mathrm{p}<0.001$, Tukey HSD). In the $\mathrm{F}_{1}$ this difference was not significant any more and instead, seeds of the west $\mathrm{CH}$ population were the heaviest $(p=0.007$ and $p=0.013$ compared with south $D$ and central $\mathrm{D}$ respectively). Altogether the coefficient of variation (CV) among Cichorium populations decreased from the parental to the $\mathrm{F}_{1}$ generation (Table 2). A decreasing CV was also observed for the seed mass of Legousia showing a large and significant difference between west $\mathrm{CH}$ and south $\mathrm{D}$ $(\mathrm{p}=0.022)$ in the parental seeds that disappeared in the $\mathrm{F}_{1}$. In the other two species, the population-by-generation interaction was not significant.
Population differentiation in germination percentage was highly significant for all species (Table 3 ). The generation main effect was also significant with Cichorium showing a lower and all other species showing a higher germination percentage in the $\mathrm{F}_{1}$ than in the parental generation (Table 3, Fig. 1). However, there is large among population variation in the generation effect, and in Echium, Cichorium and Origanum, the highly significant population-by-generation interaction indicates a contribution of environmental maternal effects to germination traits. The results can not be simply explained by a reduction in population differentiation from parental to $\mathrm{F}_{1}$ generation. A clear reduction of the $\mathrm{CV}$ was only apparent in Origanum whereas differences were small in Echium and Cichorium (Fig. 1). Instead, the significant population-bygeneration interaction in germination of the latter two species was due to a change in population ranking. In Echium, parental seeds of the UK population showed a significantly lower germination than those of other populations ( $\mathrm{p}$-values between $<0.001$ and 0.0012 ) while $\mathrm{F}_{1}$ seeds of the same population germinated significantly better than those of the west $\mathrm{CH}$ population $(\mathrm{p}=0.047)$ and differences to the other populations were not significant any more. A similar trend was observed for the south $\mathrm{D}$ population of Cichorium, which germinated significantly less than the central D population $(\mathrm{p}<0.001)$ in the parental germination but not in the $\mathrm{F}_{1}$. Instead the west $\mathrm{CH}$ population showed a lower germination $(\mathrm{p}<0.001)$ in the $\mathrm{F}_{1}$ which was not significantly different in the parental generation. Contrary to the results on seed mass the population-by-generation-interaction was not significant for Legousia although a small decrease in the $\mathrm{CV}$ was found between parental and $\mathrm{F}_{1}$ generation.

In Origanum, the particularly strong increase in germination of UK seeds from parental to $\mathrm{F}_{1}$ generation was partly due to a previous loss of germinability during two years of storage that was greater than in other populations. The result indicated that a part of the population-by-generation interaction can be explained by a differential storage response among populations. However, a previous test on freshly

Table 2. Contribution of the maternal environment to population differentiation in seed mass.

(a) Change in among-population variation from parental to $F_{1}$ generation: means $(\mathrm{mg})$ and coefficients of variation

\begin{tabular}{|c|c|c|c|c|c|c|c|c|}
\hline & \multicolumn{2}{|c|}{ Legousia s.-veneris } & \multicolumn{2}{|c|}{ Echium vulgare } & \multicolumn{2}{|c|}{ Cichorium intybus } & \multicolumn{2}{|c|}{ Origanum vulgare } \\
\hline & Parental & $\mathrm{F}_{1}$ & Parental & $\mathrm{F}_{1}$ & Parental & $\mathrm{F}_{1}$ & Parental & $\mathrm{F}_{1}$ \\
\hline West $\mathrm{CH}$ & 0.224 & 0.200 & 2.899 & 2.810 & 1.030 & 1.250 & 0.076 & 0.064 \\
\hline East $\mathrm{CH}$ & 0.203 & 0.209 & 2.818 & 2.828 & 1.318 & 1.202 & 0.076 & 0.075 \\
\hline South D & 0.188 & 0.209 & 2.426 & 2.463 & 1.013 & 1.014 & 0.087 & 0.079 \\
\hline Central D & - & - & 2.652 & 2.598 & 1.010 & 1.026 & 0.082 & 0.070 \\
\hline UK & - & - & 2.900 & 2.507 & - & - & 0.071 & 0.059 \\
\hline Coefficient of variation & 0.088 & 0.026 & 0.070 & 0.100 & 0.137 & 0.107 & 0.080 & 0.120 \\
\hline (b) Analysis of variance & & & & & & & & \\
\hline
\end{tabular}

\begin{tabular}{|c|c|c|c|c|c|c|c|c|c|}
\hline & \multirow[b]{2}{*}{ DF } & \multicolumn{2}{|c|}{ Legousia s.-veneris } & \multicolumn{2}{|c|}{ Echium vulgare } & \multicolumn{2}{|c|}{ Cichorium intybus } & \multicolumn{2}{|c|}{ Origanum vulgare } \\
\hline & & MS & $\mathrm{F}$ & MS & $\mathrm{F}$ & MS & $\mathrm{F}$ & MS & $\mathrm{F}$ \\
\hline Generation (G) & 1 & 0.000 & 0.018 & 0.287 & 2.578 & 0.022 & 0.922 & 0.002 & $18.273^{* * *}$ \\
\hline Population (P) & $4^{\mathrm{a}}$ & 0.001 & 1.679 & 0.656 & $5.898^{* * *}$ & 0.328 & $13.847^{* * *}$ & 0.001 & $8.997 * * *$ \\
\hline$G \times P$ & $4^{a}$ & 0.003 & $4.823^{*}$ & 0.178 & 1.600 & 0.117 & $4.922^{* *}$ & 0.000 & 1.068 \\
\hline Error & $110^{\mathrm{b}}$ & 0.001 & & 0.111 & & 0.024 & & 0.000 & \\
\hline
\end{tabular}

aLegousia speculum-veneris: $\mathrm{DF}=2$. Cichorium intybus: $\mathrm{DF}=3$.

'Legousia speculum-veneris: DF $=66$. Cichorium intybus: $\mathrm{DF}=88$. 
Table 3. ANOVA on the contribution of the maternal environment to population differentiation in growth chamber germination

\begin{tabular}{|c|c|c|c|c|c|c|c|c|c|}
\hline & \multirow[b]{2}{*}{ DF } & \multicolumn{2}{|c|}{ Legousia s.-veneris } & \multicolumn{2}{|c|}{ Echium vulgare } & \multicolumn{2}{|c|}{ Cichorium intybus } & \multicolumn{2}{|c|}{ Origanum vulgare } \\
\hline & & MS & $\mathrm{F}$ & MS & $\mathrm{F}$ & MS & $\mathrm{F}$ & MS & $\mathrm{F}$ \\
\hline Generation (G) & 1 & 0.168 & $5.101 *$ & 0.759 & $29.018^{* * *}$ & 0.243 & $8.643^{* *}$ & 0.257 & $10.247^{* *}$ \\
\hline Population $(\mathrm{P})$ & $4^{\mathrm{a}}$ & 0.874 & $26.584^{* * *}$ & 0.246 & $9.385^{* * *}$ & 0.479 & $17.043^{* * *}$ & 1.076 & $42.910^{* * *}$ \\
\hline$G \times P$ & $4^{\mathrm{a}}$ & 0.058 & 1.777 & 0.234 & $8.943^{* * *}$ & 0.117 & $4.151^{* *}$ & 0.852 & $33.976^{* * *}$ \\
\hline Error & $110^{\mathrm{b}}$ & 0.033 & & 0.026 & & 0.028 & & 0.025 & \\
\hline
\end{tabular}

aLegousia speculum-veneris: $D F=2$. Cichorium intybus: $D F=3$.

${ }^{b}$ Legousia speculum-veneris: $D F=66$. Cichorium intybus: $D F=88$.

collected parental seeds also revealed a highly significant population-by-generation interaction $(\mathrm{F}=4.908, \mathrm{p}=$ $0.001)$. Population differentiation was smaller in freshly collected parental seeds $(\mathrm{CV}=0.241)$ than in stored parental seeds (Fig. 1) but still twice as high as in $F_{1}$ seeds.

\section{Are maternal environmental effects mediated by seed mass?}

The different patterns of population-by-generation interactions for seed mass and for germination already suggest that the contribution of environmental maternal effects to germination is not predominantly mediated by seed mass, as only in Cichorium, the interaction was significant for both traits (Table 2b, 3).

Fitting seed mass as a covariate in the analysis on germination percentage did not reduce the level of significance in population-by-generation-interactions (Table 4) indicating that environmental maternal effects on germination were independent of seed mass. In Legousia fitting of seed mass revealed a significant interaction that was not significant in the reduced model. This could be explained by contrasting effects of seed mass mediated maternal provisioning and non resource environmental factors of the maternal environment. The latter would then only be visible after correction for maternal provisioning. The correlation of seed mass and
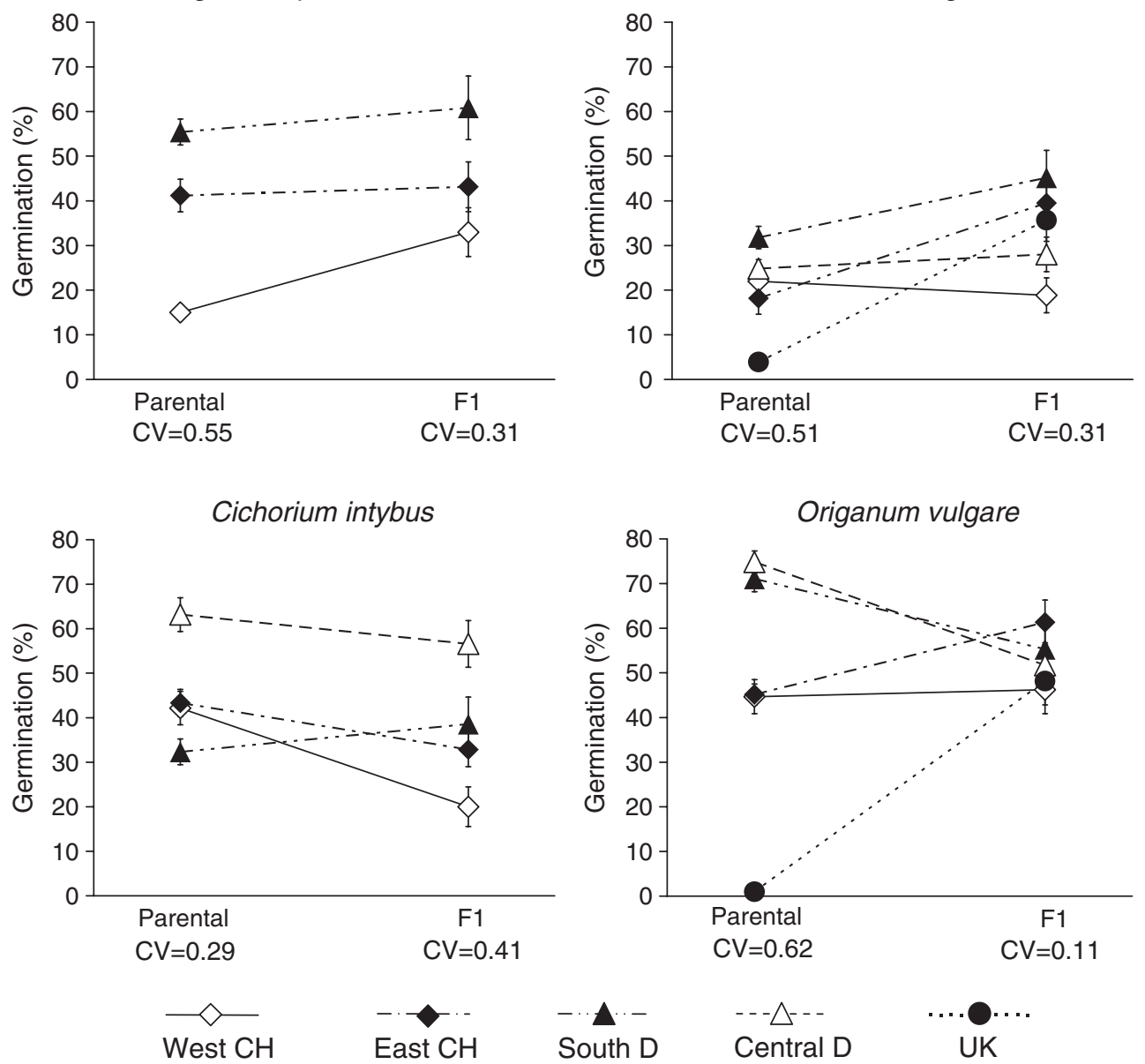

Figure 1. Comparison of population differentiation in growth chamber germination of parental and $\mathrm{F}_{1}$ seed; the coefficient of variation $(\mathrm{CV})$ indicates the among population variation; $\pm \mathrm{SE}$. 
Table 4. Change in p-values of ANOVA on growth chamber germination by fitting seed mass as a covariate; $\uparrow / \downarrow$ indicate a significant positive/negative relationship of covariate and response variable.

\begin{tabular}{|c|c|c|c|c|c|c|c|c|c|}
\hline & \multirow[b]{2}{*}{ DF } & \multicolumn{2}{|c|}{ Legousia s.-veneris } & \multicolumn{2}{|c|}{ Echium vulgare } & \multicolumn{2}{|c|}{ Cichorium intybus } & \multicolumn{2}{|c|}{ Origanum vulgare } \\
\hline & & - covar. & + covar. & - covar. & + covar. & - covar. & + covar. & - covar. & + covar. \\
\hline Seed mass & 1 & & $0.006 \uparrow$ & & $<0.001 \downarrow$ & & $0.002 \uparrow$ & & $<0.001 \uparrow$ \\
\hline Generation (G) & 1 & 0.027 & 0.023 & $<0.001$ & $<0.001$ & 0.004 & 0.001 & 0.002 & $<0.001$ \\
\hline Population (P) & $4^{\mathrm{a}}$ & $<0.001$ & $<0.001$ & $<0.001$ & $<0.001$ & $<0.001$ & $<0.001$ & $<0.001$ & $<0.001$ \\
\hline$G \times P$ & $4^{\mathrm{a}}$ & 0.177 & 0.023 & $<0.001$ & $<0.001$ & 0.008 & 0.001 & $<0.001$ & $<0.001$ \\
\hline
\end{tabular}

aLegousia speculum-veneris: $\mathrm{DF}=2 . \quad$ Cichorium intybus: $\mathrm{DF}=3$.

germination percentage was positive in Legousia, Cichorium and Origanum but surprisingly negative in Echium.

\section{Performance in the field}

Populations of Origanum differed significantly in field emergence, leaf number and shoot length but not in biomass (Table 5). The generation main effect was not significant. A significant population-by-generation interaction was only observed in field germination and this was due a change in population ranking (Fig. 2). In the parental generation, germination of the UK population was significantly lower than that of the other populations ( $\mathrm{p}$ between 0.05 and $<0.001$, Tukey HSD). In the $F_{1}$ the UK population showed the highest germination and the difference was significant compared to the west $\mathrm{CH}$ population in which germination had decreased $(\mathrm{p}<0.001)$. The $\mathrm{CV}$ for field germination decreased from the parental to the $\mathrm{F}_{1}$ generation but the effect was much smaller than in growth chambers under controlled conditions (Figs. 1, 2). A decrease in population differentiation was also visible in vegetative traits but the effect was not strong and population ranking did not change (Fig. 2). Neither in the parental nor in the $F_{1}$ generation, a superiority of the local population (west $\mathrm{CH}$ ) was observed.

In Legousia parental and $\mathrm{F}_{1}$ seeds were sown in different years, and due to great differences in environmental conditions between years, we observed a highly significant 'generation' effect for all measured traits. The performance was much lower in the $F_{1}$ plants that suffered from long lasting drought and heat in 2003. Nevertheless, the results were consistent with those of Origanum in terms of the population-by-generation interaction. This interaction was highly significant for field germination $(\mathrm{F}=18.45, \mathrm{p}<0.001)$ but not for vegetative growth and reproduction. Contrary to Origanum, among population $\mathrm{CV}$ for field germination decreased strongly from the parental $(\mathrm{CV}=0.51)$ to the $\mathrm{F}_{1}$ generation $(\mathrm{CV}=0.17)$ whereas the $\mathrm{CV}$ of vegetative traits and reproduction did not change. In the parental generation, field germination of the west $\mathrm{CH}$ population was significantly lower than that of other populations $(p<0.001)$, but no such difference was found in the $\mathrm{F}_{1}$ generation.

\section{Discussion}

\section{Environmental maternal effects in early stages of plant development}

We found highly significant differences among populations in germination percentage (all four test species) and in seed mass (three species). Population variation in early traits of plant development is common among plant species (Schütz and Milberg 1997, Keller and Kollmann 1999, Bischoff et al. 2006a). It can be genetically determined because selection favours appropriate responses to local environmental cues that synchronise germination with periods of optimum seedling survival (Linhart and Grant 1996, Baskin and Baskin 1998). However, seed mass and germination are also known to be largely affected by the maternal environment (Roach and Wulff 1987, Gutterman 1992, Sultan 1996, Baskin and Baskin 1998).

In our study, we detected a strong contribution of environmental maternal effects to population differentiation in three (germination) and two species (seed mass) respectively, indicated by significant population-by-generation interactions in a comparison of original parental seeds and $\mathrm{F}_{1}$ seeds that were produced under homogeneous conditions. The significant interactions could be partly explained by a reduction of among-population variation in the $\mathrm{F}_{1}$-generation. This finding is in line with the theory of maternal provisioning predicting an increased quality and germination of seeds grown in a favourable maternal environment (Sultan 1996, Donohue and Schmitt 1998, Riginos et al. 2007). If maternal provisioning differs between original collection sites (populations),

Table 5. ANOVA on the contribution of the maternal environment to population differentiation in the performance of Origanum vulgare in the field.

\begin{tabular}{|c|c|c|c|c|c|c|c|c|c|}
\hline & \multirow[b]{2}{*}{ DF } & \multicolumn{2}{|c|}{ Field germination } & \multicolumn{2}{|c|}{ Leaves per plant } & \multicolumn{2}{|c|}{ Shoot length } & \multicolumn{2}{|c|}{ Biomass } \\
\hline & & MS & $\mathrm{F}$ & MS & $\mathrm{F}$ & MS & $\mathrm{F}$ & MS & $\mathrm{F}$ \\
\hline Generation $(\mathrm{G})$ & 1 & 0.003 & 2.176 & 0.000 & 0.009 & 0.004 & 0.065 & 0.000 & 0.003 \\
\hline Population (P) & $3^{a}$ & 0.008 & $5.333^{* * *}$ & 0.066 & $3.336^{*}$ & 0.199 & $3.279^{*}$ & 0.116 & 2.167 \\
\hline$G \times P$ & $3^{a}$ & 0.016 & $11.567^{* * *}$ & 0.018 & 0.922 & 0.070 & 1.145 & 0.012 & 0.220 \\
\hline Block & 7 & 0.006 & $4.136^{* * *}$ & 0.039 & 1.976 & 0.098 & 1.607 & 0.076 & 1.416 \\
\hline Error & $49^{b}$ & 0.001 & & 0.020 & & 0.061 & & 0.054 & \\
\hline
\end{tabular}

aField germination: $\mathrm{DF}=4$.

bField germination: $\mathrm{DF}=63$. 

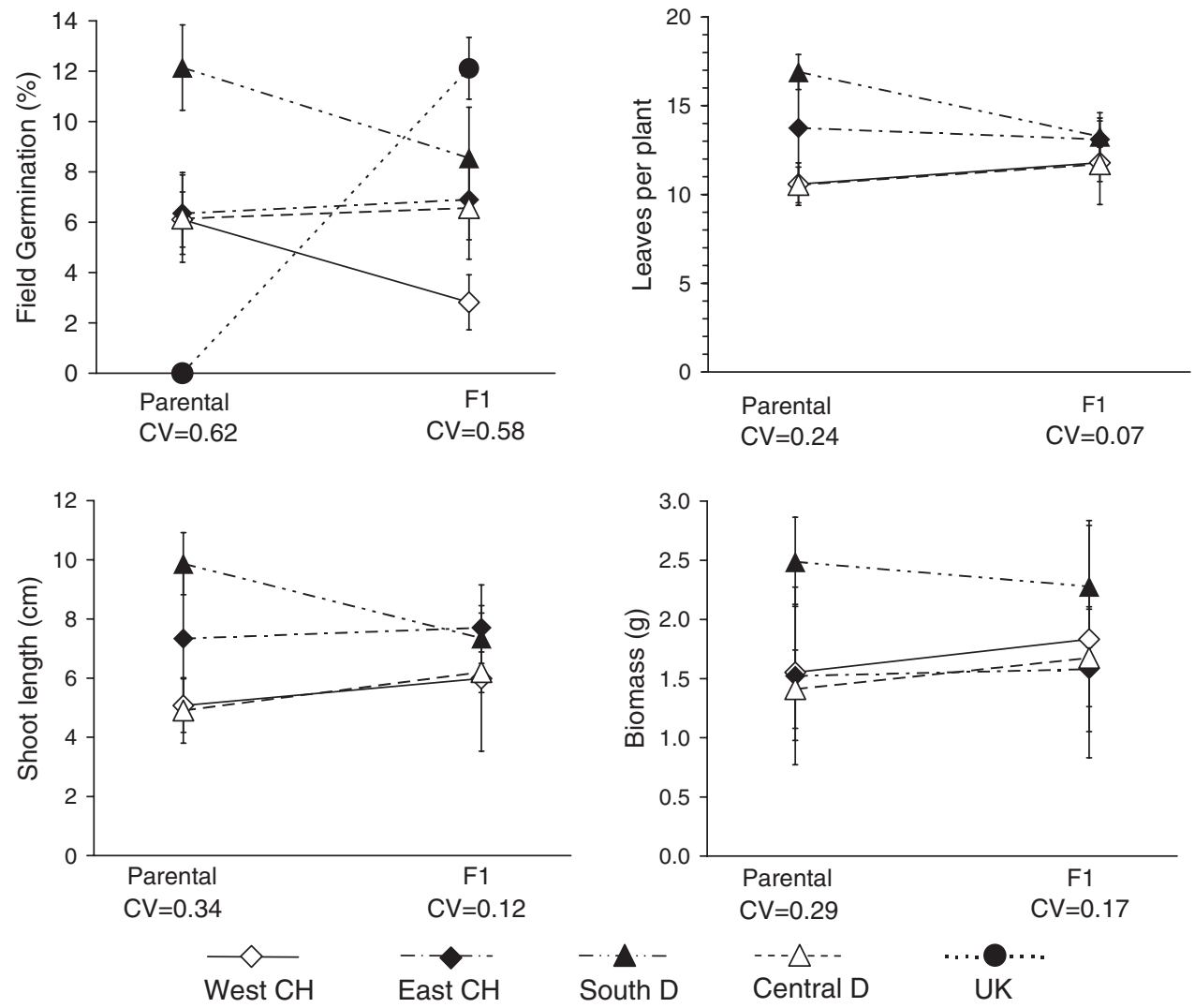

Figure 2. Comparison of population differentiation in the performance of parental and $\mathrm{F}_{1}$ plants of Origanum vulgare in the field; the coefficient of variation $(\mathrm{CV})$ indicates the among population variation; $\pm \mathrm{SE}$.

we expect population differentiation to decrease in offspring of plants grown under the same environmental conditions. However, changes in population ranking between parental and $F_{1}$ generation as well as different patterns of populationby-generation interactions in seed mass and germination indicate environmental maternal effects beyond maternal provisioning. Environmental cuing of germination through maternal effects that are independent of maternal provisioning has been demonstrated in many studies (reviewed by Roach and Wulf 1987, Baskin and Baskin 1998, Munir et al. 2001, Donohue et al. 2005). Such non-resource maternal effects may be adaptive in the home environment but non-adaptive in other environments (Galloway and Etterson 2007). Homogenisation of the maternal environment to produce $\mathrm{F}_{1}$ seeds changed the environmental cuing in our study which may have led to a population-dependent differential change in germination percentage.

This study is to our knowledge the first one that directly analyses the contribution of environmental maternal effects to population differentiation in plants by simultaneously testing parental seed directly collected from the field and $\mathrm{F}_{1}$ seed grown under homogeneous conditions. However, several studies comparing genotypes previously grown in different maternal environments seem to support our finding that non-genetic maternal effects can significantly contribute to population differentiation in early traits. Sultan (1996) found that environmental maternal effects on seed mass and germination are often larger than genotype effects but she compared genotypes of the same population representing a relatively low genetic variation. In a reciprocal transplant experiment analysing different populations and different maternal environments, Hereford and Moriuchi (2005) found that both significantly affected seed mass and germination but the magnitude of the population effect was greater. A relatively large effect of the maternal environment was found in a germination study testing populations from different alpine elevations that had previously been grown at several natural and non natural sites (Hermesh and Acharya 1992).

\section{Environmental maternal effects in later stages of plant development}

In agreement with most other studies, we found that the contribution of environmental maternal effects decreased in later stages of plant development. In both species tested in the field, Orignaum and Legousia, the population-bygeneration interaction was only significant for field emergence but not for vegetative growth and reproduction. In Origanum, a small decrease in variation of vegetative traits was observed while in Legousia the variation of all measured late traits remained constant in the $\mathrm{F}_{1}$.

Several studies detected significant environmental maternal effects in later stages of the life cycle, including plant growth, reproduction (Schmid and Dolt 1994, Helenurm and Schaal 1996, Weiner et al. 1997, Riginos et al. 2007), plant 
defence traits (Agrawal 2002, Holeski 2007) and phenology (Johnsen et al. 2005). Some environmental maternal effects were found to persist even more than one generation (Wulff et al. 1999, Molinier et al. 2006, Rohde and Juntilla 2008). Growth and reproduction may be indirectly affected by maternal provisioning due to differences in seedling performance (Roach and Wulff 1987). Studies demonstrating a positive relationship between seed mass and offspring fitness confirm the possibility of such indirect environmental maternal effects on later traits (Stanton 1984, Meyer and Carlson 2001). It is obvious that effects based on maternal provisioning diminish in later stages of the life cycles because growth and reproduction depend on many other variables. Accordingly, all studies cited above found a reduction in environmental maternal effects over time and often, they became insignificant directly after germination (Hereford and Moriuchi 2005). Effects on plant defence and phenology cannot simply be explained by maternal provisioning. It has been suggested that maternally induced epigenetic and/or hormonal changes can be responsible (Agrawal 2002, Gianoli 2002, Johnson et al. 2005, Holeski 2007). In particular, epigenetic changes are potentially more stable than effects of maternal provisioning and may persist over several generations (Molinier et al. 2006, Rohde and Juntilla 2008). However, even such physiological changes may rapidly disappear if offspring and maternal environment are different (Agrawal 2002).

Studies allowing a comparison between genetic and environmental maternal effects on offspring performance beyond germination as well as analyses of the contribution of maternal effects to population differentiation are still rare. In general, little influence of the maternal environment compared with genotype effects has been found (Weiner et al. 1997, Hereford and Moriuchi 2005, Holeski 2007). This is particularly the case if genotypes belong to different populations (Hereford and Moriuchi 2005, Holeski 2007) confirming our result that different maternal environments did not significantly contribute to population differentiation in post-germination traits. These findings may lead to the conclusion that population differentiation in plant fitness is finally not much affected by differences in the maternal environment. However, the evaluation of effects on plant fitness strongly depends on the importance of seedling recruitment in the life cycle. Short lived plants of disturbed habitats are often recruitment limited and thus germination percentage as well as timing and speed may be crucial for population growth rates. Under such conditions, environmental maternal effects on germination may largely affect fitness (Baskin and Baskin 1998, Hereford and Moriuchi 2005, Luzuriaga et al. 2006). Galloway and Etterson (2007) demonstrated that offspring of Campanula americana have greater germination rates leading to increased fitness $(\lambda)$ when planted to their maternal light environment compared with plants mismatching their maternal light environment. The importance of seedling recruitment in determining fitness differences among populations has also been shown for perennial plants (Bischoff et al. 2006b).

\section{Accounting for maternal effects in studies on population differentiation}

The correction for seed mass is used as a standard method to account for environmental maternal effects in studies on genetic differentiation (Roach and Wulff 1987, Donohue and Schmitt 1998, Galloway 2001, Pico et al. 2004). Seed mass is supposed to be a measure for maternal provisioning that is correlated with germination percentage and seedling performance (Stanton 1984, Meyer and Carlson 2001). Including seed mass as a covariate in analyses of genetic differentiation should therefore correct for a large part of the bias caused by environmental maternal effects (Helenurm and Schaal 1996, Pico et al. 2003). In our study, populationby-generation interactions for germination percentage remained highly significant after fitting seed mass as a covariate. This result supports several other recent studies that were unable to reduce environmental maternal effects on later traits when correcting for seed mass. Some experiments already failed to detect a significant effect of the maternal environment on seed mass (Gianoli 2002, Luzuriaga et al. 2006), in others seed mass had no effect on offspring traits (Pico et al. 2004). In our study, we were not able to detect maternal effects on seed mass of Origanum and Echium. In the other two species, Legousia and Cichorium, we observed maternal effects on seed mass and a positive correlation of seed mass and germination but accounting for seed mass did not reduce environmental maternal effects on these traits. Similarly, Agrawal (2002) and Hereford and Moriuchi (2005) failed to remove maternal effects on offspring traits by using this correction method although such effects on seed mass were significant.

Thus, correcting for seed mass seems to be generally insufficient to reduce environmental maternal effects from population differentiation in plant traits. Moreover, the method may also remove a part of the genetic variation among populations. In three species, we observed a significant population effect in the $\mathrm{F}_{1}$ generation indicating a strong genetic differentiation in seed mass. Similar results have been found in other studies (Weiner et al. 1997, Galloway 2001, Hereford and Moriuchi 2005). Statistical models including seed mass as a covariate may therefore largely underestimate genetic differentiation in germination, offspring growth or reproduction. Accounting for differences in initial plant size is probably a more efficient method to remove environmental maternal effects from population differentiation in later traits, but the risk not to detect existing genetic variation increases. The standardization of initial size by selecting juveniles of the same size would be even more problematic because information on variation due to initial size differences would be lost. The most straightforward method to account for maternal effects is the growth of at least one generation in a standard environment. This may also induce maternal effects but at least maternal provisioning of following generations should be very similar among populations (Kawecki and Ebert 2004). Nevertheless, this method has rarely been used to correct for environmental maternal effects in plants (Galloway and Fenster 2000, Santamaria et al. 2003) because the production of $F_{1}$ seeds is time consuming for biennials and perennials that do not flower in the first year.

The need to account for environmental maternal effects and the appropriate method depend on the scientific questions to be answered. In analyses of late developmental traits in long-lived species, genetic differences accounting for environmental maternal effects may not be required because their contribution to population differentiation is relatively small. 
However, studies on early traits usually need to account for environmental maternal effects even in long-lived species, and growth of $\mathrm{F}_{1}$ seeds under standard conditions should be the preferred method. Comparisons focussing on plant fitness would require such a correction if seedling recruitment is limiting population growth rates. Finally, in applied studies comparing the success of different populations for restoration or re-vegetation purposes (Keller and Kollmann 1999, Hufford and Mazer 2003, Smith et al. 2005, Bischoff et al. 2006a) environmental maternal effects represent an important part of the differentiation that greatly influence establishment at the target sites. Removing these effects from population comparisons may lead to unrealistic performance estimates. In particular, restoration measures starting from bare ground depend on seedling recruitment and are sensitive to environmental maternal effects. Thus environmental maternal effects may not only be a bias in population studies, they are part of the natural differentiation and may be even adaptive.

Acknowledgements - We thank Franziska Leuenberger for her assistance and great commitment to lab and field work. Beatrice Vonlanthen was responsible for the initial phase of growing second generation plants. We further thank Lus Escher, Sabine Röthlin, Patrick Freund, Martin Künzle und Renate Zindel for field assistance. This study was supported by the National Centre of Competence in Research (NCCR) Plant Survival, research programme of the Swiss National Science Foundation.

\section{References}

Agrawal, A. A. 2002. Herbivory and maternal effects: mechanisms and consequences of transgenerational induced plant resistance. - Ecology 83: 3408-3415.

Baskin, J. M. and Baskin, C. C. 1998. Seeds. Ecology, biogeography and evolution of dormancy and germination. - San Diego Academic Press.

Becker, U. et al. 2006. Local adaptation in the monocarpic perennial Carlina vulgaris at different spatial scales across Europe. Oecologia 150: 506-518.

Bischoff, A. et al. 2006a. Seed provenance matters - effects on germination of four plant species used for ecological restoration. - Basic Appl. Ecol. 7: 347-359.

Bischoff, A. et al. 2006b. Detecting local adaptation in widespread grassland species - the importance of scale and local plant community. - J. Ecol. 94: 1130-1142.

Bischoff, A. et al. in press. The importance of plant provenance and genotypic diversity of seed material used for ecological restoration. - Restor. Ecol. doi: 10.1111/j.1526-100X. 2008.00454.x.

Bossdorf, O. et al. 2008. Epigenetics for ecologists. - Ecol. Lett. 11: 106-115.

Donohue, K. and Schmitt, J. 1998. Maternal environment effects in plants: adaptive plasticity. - In: Mousseau, T. A. and Fox, C. W. (eds), Maternal effects as adaptations. Oxford Univ. Press, pp. $137-158$.

Donohue, K. et al. 2005. Environmental and genetic influences on the germination of Arabidopsis thaliana in the field. - Evolution 59: 740-757.

Galloway, L. F. 2001. The effect of maternal and paternal environments on seed characters in the herbaceous plant Campanula americana. - Am. J. Bot. 88: 832-840.

Galloway, L. F. and Fenster, C. B. 2000. Population differentiation in an annual legume: local adaptation. - Evolution 54: 1173-1181.
Galloway, L. F. and Etterson, J. R. 2007. Transgenerational plasticity is adaptive in the wild. - Science 318: 1134-1136.

Gianoli, E. 2002. Maternal environmental effects on the phenotypic responses of the twining vine Ipomoea purpurea to support availability. - Oikos 99: 324-330.

Gutterman, Y. 1992. Maternal effects on seeds during development. - In: Fenner, M. (ed.), Seeds: the ecology of regeneration in plant communities. Melksham Redwood Press, pp. 27-59.

Hardy, O. J. et al. 2004. Fine-scale genetic structure and gene dispersal in Centaurea corymbosa (Asteraceae) L. I. Pattern of pollen dispersal. - J. Evol. Biol. 17: 795-806.

Helenurm, K. and Schaal, B. A. 1996. Genetic and maternal effects on offspring fitnessin Lupinus texensis (Fabaceae). - Am. J. Bot. 83: 1596-1608.

Hereford, J. and Moriuchi, K. S. 2005. Variation among populations of Diodia teres (Rubiaceae) in environmental maternal effects. - J. Evol. Biol. 18: 124-131.

Hermesh, R. and Acharya, S.N. 1992. Influence of maternal plant environment and provenance of alpine bluegrass seed germination. - Can. J. Plant Sci. 72: 801-808.

Holeski, L. M. 2007. Within and between generation phenotypic plasticity in trichome density in Mimulus guttatus. - J. Evol. Biol. 20: 2092-2100.

Hufford, K. M and Mazer, S. J. 2003. Plant ecotypes: genetic differentiation in the age of ecological restoration. - Trends Ecol. Evol. 18: 147-155.

Johnsen, Ø. et al. 2005. Daylength and temperature during seed production interactively affect adaptive performance of Picea abies progenies. - New Phytol. 168: 589-596.

Kalisz, S. and Purugganan, M. D. 2004. Epialleles via DNA methylation: consequences for plant evolution. - Trends Ecol. Evol. 19: 309-314.

Kawecki, T. and Ebert, D. 2004. Conceptual issues in local adaptation. - Ecol. Lett. 7: 1225-1241.

Keller, M. and Kollmann, J. 1999. Effects of seed provenance on germination of herbs for agricultural compensation sites. Agric. Ecosyst. Environ. 72: 87-99.

Linhart, Y. B. and Grant, M. C. 1996. Evolutionary significance of local genetic differentiation in plants. - Annu. Rev. Ecol. Syst. 27: 237-277.

Luzuriaga, A. L. et al. 2006. Environmental maternal effects on seed morphology and germination in Sinapis arvensis (Cruciferae). - Weed Res. 46: 163-174.

Macel, M. L. et al. 2007. Aboveground versus below-ground factors in local adaptation of two common plant species. - Ecology 88: 424-433.

Marshall, D. J. and Uller, T. 2007. When is a maternal effect adaptive? - Oikos 2007: 1957-1963.

Meyer, S. E. and Carlson, S. L. 2001. Achene mass variation in Ericameria nauseosus (Asteraceae) in relation to ndispersal abiligty and seedling fitness. - Funct. Ecol. 15: 274-281.

Molinier, J. et al. 2006. Transgeneration memory of stress in plants. - Nature 442: 1046-1049.

Munir, J. et al. 2001. The influence of maternal photoperiod on germination requirements in Arabidopsis thaliana. - Am. J. Bot. 88: 1240-1249.

Pico, F. X. et al. 2003. Fitness traits and dispersal ability in the herb Tragopogon pratensis (Asteraceae): decoupling the role of inbreeding depression and maternal effects. - Plant Biol. 5: 522-530.

Pico, F. X. et al. 2004. Influence of selfing and maternal effects on life cycle traits and dispersal ability in the herb Hypochaeris radicata (Asteraceae). - Bot. J. Linn. Soc. 146: 163-170.

Riginos, R. et al. 2007. Maternal effects of drought stress and inbreeding in Impatiens capensis (Balsaminaceae). - Am. J. Bot. 94: 1984-1991.

Roach, D. A. and Wulff, R. D. 1987. Maternal effects in plants. Annu. Rev. Ecol. Syst. 18: 209-235. 
Rhode, A. and Juntilla, O. 2008. Remembrances of an embryo: long-term effects on phenology traits in spruce. - New Phytol. 177: 2-5.

Santamaria, L. et al. 2003. Plant performance across latitude: the role of plasticity and local adaptation in an aquatic plant. Ecology 84: 2454-2461.

Schmid, B. and Dolt, C. 1994. Effects of maternal and paternal environment and genotype on offspring phenotype in Solidago altissima L. - Evolution 48: 1525-1549.

Schütz, W. and Milberg, P. 1997. Seed dormancy in Carex canescens: regional differences and ecological consequences. - Oikos 78: 420-428.

Slatkin, M. 1985. Gene flow in natural populations. - Annu. Rev. Ecol. Syst. 16: 393-430.
Smith, B. M. et al. 2005. The effect of provenance on the establishment and performance of Lotus corniculatus L. in a re-creation environment. - Biol. Conserv. 125: 37-46.

Stanton, M. L. 1984. Seed variation in wild radish: effect of seed size on components of seedling and adult fitness. - Ecology 65: 1102-1112.

Sultan, S. E. 1996. Phenotypic plasticity for offspring traits in Polygonum persicaria. - Ecology 77: 1791-1807.

Weiner, J. et al. 1997. How important are environmental maternal effects in plants? A study with Centaurea maculosa. - J. Ecol. 85: $133-142$.

Wulff, R. D. et al. 1999. Intraspecific variability and maternal effects in the response to nutrient addition in Chenopodium album. - Can. J. Bot. 77: 1150-1158. 